\title{
Correlation Assessment of NDVI and Land use Dynamics with Water Resources for the Southern Margin of Mu Us Sandy Land, China
}

\section{Menglong Zhao}

Yellow River Engineering Consulting Co Ltd

\section{Yu Wang}

Yellow River Conservancy Committee: Yellow River Conservancy Commission

Siyuan Liu ( $\square$ liusiyuan22@126.com )

Xi'an University of Technology https://orcid.org/0000-0002-1092-4456

\section{Ping-an Zhong}

Hohai University

\section{Hongzhen Liu}

Yellow River Engineering Consulting Co Ltd

\section{Rongrong Li}

Yellow River Engineering Consulting Co Ltd

\section{Research Article}

Keywords: Mu Us Sandy Land, water scarcity, NDVI, land use, impulse response function

Posted Date: May 24th, 2021

DOI: https://doi.org/10.21203/rs.3.rs-483664/v1

License: (1) This work is licensed under a Creative Commons Attribution 4.0 International License. Read Full License

Version of Record: A version of this preprint was published at Environmental Science and Pollution Research on October 16th, 2021. See the published version at https://doi.org/10.1007/s11356-02116757-3. 


\title{
Correlation assessment of NDVI and land use dynamics with water resources for
}

\section{the southern margin of Mu Us Sandy Land, China}

\author{
Menglong Zhao ${ }^{\mathrm{a}, \mathrm{b}}$, Yu Wang ${ }^{\mathrm{c}}$, Siyuan Liu ${ }^{\mathrm{d},}$, Ping-an Zhong ${ }^{\mathrm{b}}$, Hongzhen Liu ${ }^{\mathrm{e}}$, Rongrong $\mathrm{Li}^{\mathrm{e}}$ \\ a Yellow River Engineering Consulting Co.,Ltd.;Postdoctoral Research Station of Yellow River \\ Engineering Consulting Co.,Ltd., Zhengzhou, Henan 450003, China \\ ${ }^{b}$ College of Hydrology and Water Resources, Hohai University, NO.1, Xikang Road, Nanjing 210098, \\ China \\ ${ }^{c}$ Yellow River Conservancy Commission of the Ministry of Water Resources, Zhengzhou, Henan \\ 450003, China \\ ${ }^{d}$ State Key Laboratory of Eco-hydraulics in Northwest Arid Region, Xi'an University of Technology, \\ Xi'an 710048, China \\ ${ }^{e}$ Yellow River Engineering Consulting Co.,Ltd., Zhengzhou, Henan 450003, China. \\ *Corresponding email: liusiyuan22@126.com
}

Abstract: To prevent desertification, countries all over the world have made diversified efforts and vegetation restoration has been proved to be an effective approach. However, for sandy land that has limited water resources, measures such as artificial vegetation, may lead to the increase risk of drought.

While affirming the achievements of sand utilization, there are many controversies exist regarding the advantages of turning deserts green, especially considering the water scarcity. Therefore, the long-run and causal relationships between sandy land, water consumption and vegetation coverage are necessary for explorations. Taken the southern margin of the Mu Us Sandy Land as the study area, this study explored the interactions between sandy land, water consumption and NDVI over a period of 2000-2018 with a VAR model approach. In the study area, various revegetation projects have made great achievements, resulting in a significant reduction of the sandy land area. In addition, the NDVI has ascend from 0.196 in 2000 to 0.371 in 2018 with a ratio of $89.3 \%$. Results showed that there exist longterm stable equilibrium and causal relationships between water consumption with sandy land and NDVI.

The increase of NDVI is relatively the direct factor causes the increase of water consumption. It could be inferred that those artificial vegetation measures may be based on large amount of water consumption, 
which may aggravate further water shortage and ecological damage. More scientific and stronger water resources management measures need to be implemented locally to achieve a balance between water resources and revegetation.

Keywords: Mu Us Sandy Land; water scarcity; NDVI; land use; impulse response function

\section{Introduction}

Desertification is one of the most serious ecological problems worldwide. Drylands cover approximately $41 \%$ of Earth's land surface and are home to more than $38 \%$ of the total global population of 6.5 billion (James et al. 2007). To cope with the issue of desertification, governments around the world have implemented various measures, such as sand fixing, revegetation (Amiraslani and Dragovich 2011), installing windbreaks, and natural sealing (Zhu et al. 1984; Bonkoungou 1996). China, which is one of the most seriously affected countries by desertification, has been implementing large-scale conservation programs, including the Key Shelterbelt Construction Program, Wildlife Conservation and Nature Reserve Development Program, Forest Eco-Compensation Program, and Natural Forest Conservation Program (Liu et al. 2008; Yin and Yin 2010). The implementation of these projects has achieved remarkable results. According to the satellite data of NASA, the global green area increased by $5 \%$ from 2000 to 2017 (equivalent to the entire Amazon rainforest). Notably, China has been leading the growth of global greening and contributes $25 \%$ of the net growth in the global vegetation area (Chen et al. 2019).

The Mu Us Sandy Land, which is located in the typical agro-pastoral transitional zone, is one of the most sensitive, vulnerable and severely degraded areas in northern China. This desert area had rich water resources and high grass coverage; however, with an increase in population and human activities, 
excessive reclamation and grazing led to water resource depletion and continuous desertification (Runnström 2003; Huang et al. 2009; Bai and Cui 2019). However, in recent years, the trend of desertification has reversed. The desertification land area of Mu Us Sandy Land reduced at an average rate of $62.37 \mathrm{~km}^{2} /$ year from 1990 to 2017 (the desertification area in 2017 was $1684.09 \mathrm{~km}^{2}$ ) (Han et al. 2019). Over the past three decades, the interannual normalized difference vegetation index (NDVI) in the Mu Us Desert mostly exhibited increasing trends due to human activity impacts (Karnieli et al. 2014; Wu et al. 2014; An et al. 2014; Li et al. 2016). The area with the most dynamic NDVI trends is distributed in the Shaanxi Province (Wu et al. 2002; Liu et al. 2020). This area occupies one-third of the area of Mu Us Sandy Land and is known as the Agro-pastoral ecotone of the Northern Shaanxi Province (ANS). According to data released by the Shaanxi Provincial Forestry Bureau on April 22, 2020 (Yulin Municipal People's Government 2020), the desertification land control rate in Yulin has reached 93.24\%, which indicates that all mobile sand dunes have been fixed, which is the kind of real realization of "sand degradation and green increase".

Due to the distinctiveness of the study location and the achievements of desertification prevention in recent years, the ANS has become a research hotspot for scholars. Numerous studies have explored the effectiveness of the aforementioned projects. Studies have explored the causes of desertification (Wu and Ci 1999; Wu 2001), conducted monitoring and evaluation of desertification (Wu and Ci 2002; Zhang et al. 2003), examined land use and land cover (LULC) changes (Zhang et al. 2012; Meng et al. 2012; Li et al. 2013), explored the trends of vegetation change (Ju et al. 2008; Karnieli et al. 2014), and conducted ecological risk and ecological vulnerability assessment in desert areas (Meng et al. 2015). However, the transformation of a natural desert ecosystem is a complex coupling process and whether it will be the causes of other changes is worth further exploration. 
Previous studies have shown that both field investigation and statistical data analysis warned us that, by the common influence of the growing human activities and still fragile eco-environment, the ecological restoration in Mu Us are experiencing increasing challenges due to the water scarcity ( $\mathrm{Li}$ et al. 2017).A previous study indicated that although revegetation has had positive effects on ecological systems in Mu Us Sandy Land, it has caused evapotranspiration to increase by $51 \mathrm{~mm}$ per summer; thus, revegetation has exacerbated water shortage in the aforementioned region (Zheng et al. 2020). In waterlimited arid areas, a reduction in water resources due to vegetation results in a reduction in the amount of water available for human activities. Consequently, the competition for water between the environment and humans is exacerbated, which results in ecological degradation (Quiggin 2001; Wu et al. 2002). Field investigations and statistical data analyses have indicated that water-scarcity-related challenges are associated with the ecological restoration of the Mu Us Desert due to growing human activities and the fragile eco-environment in this region ( $\mathrm{Li}$ et al. 2016, 2017). For sandy land that has limited water resources and is prone to a high degree of drought, measures, such as artificial vegetation, may lead to the increase of water consumption and then a new crisis of desertification. While affirming the achievements of sand utilization, there are many controversies exist regarding the advantages of turning deserts green, especially considering the scarcity of water resources in these areas. Therefore, will the degradation of sandy land lead to a substantial increase in water resources consumption and vegetation growth is necessary for consideration.

To address this issue, this study takes the ANS as the study area and aims (1) to analyze the change of land use in the study area and clarify the conversion relationship between sandy land and other land types, (2) to explore NDVI changes in the ANS, and (3) to access the dynamic relationships among sandy land, water resources, and the NDVI by using the vector autoregression (VAR) model. This study is expected 

area.

\section{Study area and data}

\subsection{Description of the study area}

In this study, the Agro-pastoral ecotone of the Northern Shaanxi Province (ANS) is taken as the study area, which occupies one-third of the area of Mu Us Sandy Land. The ANS is located in northwest China (ranging from $107^{\circ} 35^{\prime}$ to $111^{\circ} 29^{\prime} \mathrm{E}$ and from $37^{\circ} 35^{\prime}$ to $39^{\circ} 02^{\prime} \mathrm{N}$ ) and has an approximate area of 33992 $\mathrm{km}^{2}$ (Figure 1). It consists of six counties, namely Yuyang, Shenmu, Fugu, Hengshan, Dingbian, and Jingbian. More than $44.2 \%$ of the study area is classified as desertified land. The considered region has a typical continental semiarid climate and water resources here are very poor. The per capita water resources are only 9.97 million $\mathrm{m}^{3}$, which is lower than the standard of water resources proposed by the United Nations Population Action Organization in 1993 for severely water-scarce countries (10 million $\mathrm{m}^{3} /$ per capita) (Wu and Ci 2002). The annual precipitation ranges from $440 \mathrm{~mm}$ in the southeast to 250 $\mathrm{mm}$ in the northwest. A total of $60 \%-80 \%$ of the annual precipitation is received from June to August. The annual mean temperature is approximately $6^{\circ} \mathrm{C}-8.5^{\circ} \mathrm{C}$, with monthly mean temperatures of $22^{\circ} \mathrm{C}$ in July and $-11^{\circ} \mathrm{C}$ in January. 


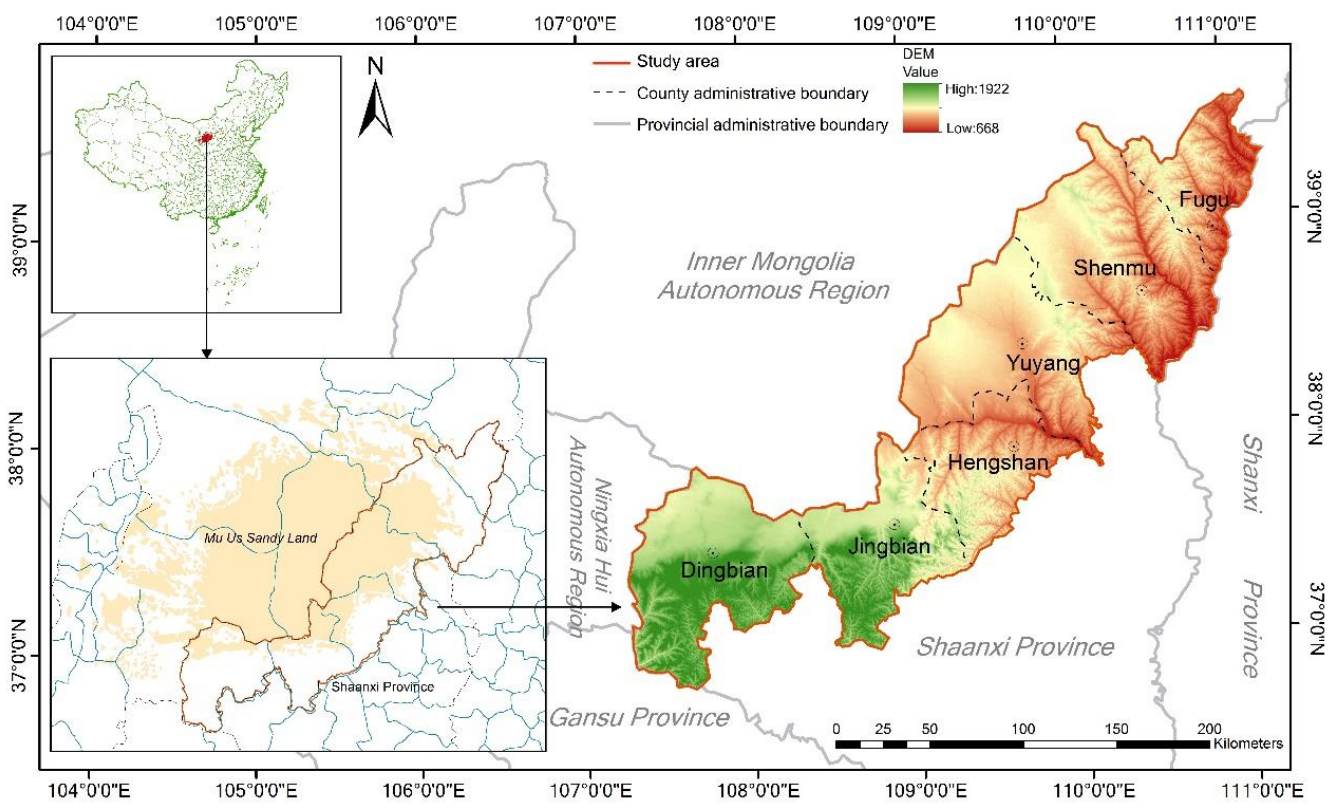

Fig.1 Location of the study area

\subsection{Data sources}

The types of land use represent the achievements of human beings in land use and transformation as well as the forms and uses (functions) of land. In this study, land use data from 1990 and 2000-2018 were used. These data were obtained from the remote sensing monitoring dataset of multiperiod LULC in China (CNLUCC). An efficient classification system was developed, and a research team from the Institute of Geographic Sciences and Natural Resources Research, Chinese Academy of Sciences, was invited to classify remote sensing image data through a human-machine interactive interpretation to achieve consistent and accurate classification (Liu et al. 2010). The NDVI is a quantitative parameter of vegetation coverage and reflects ecological environmental quality. Monthly average NDVI data were calculated from the spatial distribution dataset of China's monthly NDVI (2000-2018). The land use and NDVI data were obtained from the Resource and Environment Data Cloud Platform, Chinese Academy of Sciences (http://www.resdc.cn/ ).

Water resource data for 2000-2018 were mainly collected from the Water Resources Bulletin of Shaanxi Province and Water Resources Statistics Bulletin of Yulin City, which are available on the 
128

129

130

131

132

133

134

135

136

137

138

websites of relevant government departments (http://slt.shaanxi.gov.cn/TJf-zxfw-Pb8-1-b9u-175 and http://slj.yl.gov.cn/index.html, respectively)

\section{Methodology}

\subsection{Analysis of land use and NDVI changes}

In order to better understanding the land cover change and NDVI trends in ANS, the evolution characteristics of land cover change and NDVI change were carried out. With ArcGIS platform, the land cover maps and NDVI change maps of 2000-2018 were overlaid, then key information on where experienced significant NDVI changes and what is the land cover type of this polygon were extracted.

Additionally, transition matrix, a classic method for detecting LUCC, has been employed for exploring dynamics of LUCC in ANS. For land cover changes of 2000-2018, the data were divided into four pairs of 2000-2005, 2005-2010, 2010-2015 and 2015-2018. For better comparison, the comparison between 1990 and 2000 has been supplemented. For each pair of compared data sets, an extended transition matrix was constructed. The maps from the initial and subsequent time were overlaid with ArcGIS to produce a matrix that provided the LULC areas by categorical transition between the two points in time. Due to the large amount of data, in order to better show the flow direction of data, Sankey chart was selected to show the data of transfer matrix.

\subsection{A VAR model approach}

The VAR model is a widely used econometrics technique for multivariate time-series modeling and proposed by Sims (1980) to analyze the mutual influence relationship between macroeconomic variables. VAR model has some very attractive features and has proven to be a valuable tool for analyzing dynamic transmission mechanisms among time-series processes (McMillan 1991; Lu 2001). In each equation of the model, endogenous variables return all lagged endogenous variable items to estimate dynamic 
150

151

152

154

155

156

158

159

160

161

162

163

164

165

166

167

relationships among all the endogenous variables. Although the VAR model was originally developed for analyzing the mutual influence relationship between macroeconomic variables, it uses simultaneous multi-equations, which are not based on economic theory and can be applied to several other fields. For example, the VAR model was used to analyze and forecast the mutual relationship between variables in a system, determine leading and potential factors, and quantify the influence of these factors (Kumar et al. 2009; Adenomon et al. 2013; Wu et al. 2018).

In addition to forecasting, VAR model equations are used to simulate the effects of sudden changes (impulses) in one variable on other variables. Such effects are quantified through impulse response function (IRF), which enable the estimation of the timescale over which changes in the water consumption, sandy land area, and NDVI affect each other. Another application of the VAR model is the variance decomposition with forecast error variance. The variance decomposition indicates what percentage of a forecast error variance can be attributed to each individual variable used in the model. The implementation of the VAR model is described in the following text.

\subsubsection{Augmented Dickey-Fuller test}

Standard Granger causality tests be conducted on stationary time series. The unit roots of $X_{t}$ are determined to confirm the stationary properties of each variable. The aforementioned unit roots are obtained using the augmented Dickey-Fuller (ADF) test (Dickey and Fuller 1979, 1981). For the time series $X_{t}$, the $\mathrm{ADF}$ relationship is expressed as follows:

$$
\Delta X_{t}=\mu+\alpha X_{t-1}+\sum_{i=1}^{k} \beta_{i} \Delta X_{t-i}+\varepsilon_{t}
$$

where $\Delta$ is the difference operator; $k$ is the autoregressive lag length, that has to be sufficiently large to eliminate possible serial correlation in $\beta_{i} ; \alpha$ and $\beta$ are the coefficients of interest. When the 
171 aforementioned variables are found to be nonstationary, ADF tests are repeated for the first and second

172 differences.

173 3.2.2 Johansen multivariate cointegration test

174 The Johansen multivariate cointegration test (Johansen and Juselius 1990) can be represented as

175 follows:

$$
\Delta Z_{t}=\mu+\prod Z_{t-1}+\sum_{i=1}^{k} \Gamma_{i} \Delta X_{t-i}+\varepsilon_{t}
$$

\subsubsection{Selection of the lag length} prediction error (FPE) and Akaike information criterion (AIC). These information criteria are statistical model fit measures (Gao 2006). They quantify the relative goodness of fit of various previously derived statistical models for a given sample of data.

\subsubsection{Impulse response function (IRF)}

Because the VAR model is a nontheoretically model, directly determining the relationship among the variables in the model from parameter matrices is difficult. The aforementioned relationships can be 
192

193

194

195

196

197

198

200

201

202

203

205

is shocked. Therefore, IRFs have been proposed as tools for interpreting VAR models. The impulse technique of response analysis involves representing the reaction of each variable to a shock in each equation of the system. IRFs can be used to reflect the effect of a random distribution term on the current and future values of endogenous variables. Thus, the dynamic effect of random disturbances on endogenous variables can be characterized. Such characterization reflects how a random disturbance influences other variables in accordance with the VAR model as well as the dynamic process of feedback to itself. IRFs with a strong time characteristic can indicate the degree of response for any new information generated by any system variable. A VAR can be modeled as a triangular moving average process, which can be written in the vector form as follows:

$$
\frac{\partial x_{t+s}}{\partial \rho_{1 t}}=\varphi_{s}
$$

where the element of $\varphi_{s}$ in row $i$ and column $j$ indicates the effect of a one-unit increase in the $j$ th variable's innovation at time $t\left(\varepsilon_{i j}\right)$ on the value of the $i$ th variable at time $t+s\left(x_{i, t+s}\right)$ when considering all other innovations at all times constant. Bootstrapped confidence intervals are commonly drawn around IRFs.

\subsubsection{Variance decomposition}

The variance decomposition is used to examine short-run dynamic interactions between model variables. The variance decomposition is used to describe a relativity effect, and it indicates how much of a forecast error variance can be attributed to each impact factor in the VAR system. Therefore, it is necessary to analyze the variance decomposition to trace the shocks to the system. The variance decomposition provides information regarding the relative importance of each random innovation in affecting the variables in the VAR model. 


\section{Results and discussion}

\subsection{Identifying the dynamic evolution in land use}

As the rapid utilization of sand land in the ANS mainly began after 2000, LULC data for 1990 were selected here for compared with those for 2000-2018 to compare land use situations before and after sandy land utilization. As displayed in Figure 2, in 1990, the main land use categories in the ANS were cultivated land, grassland, and sandy land. The other land types occupied a limited area. The area of sandy land has decreased significantly since 1990, and sandy land has been gradually occupied by arable land and grassland. This trend remains the same after 2000. Moreover, the area of urban and rural construction land has increased rapidly, especially after 2000, which indicates that human activities have increased significantly in the study area. These human activities are concentrated in the marginal zone of sandy land distribution, which further proves that the scale of sand land utilization measures is gradually expanding.
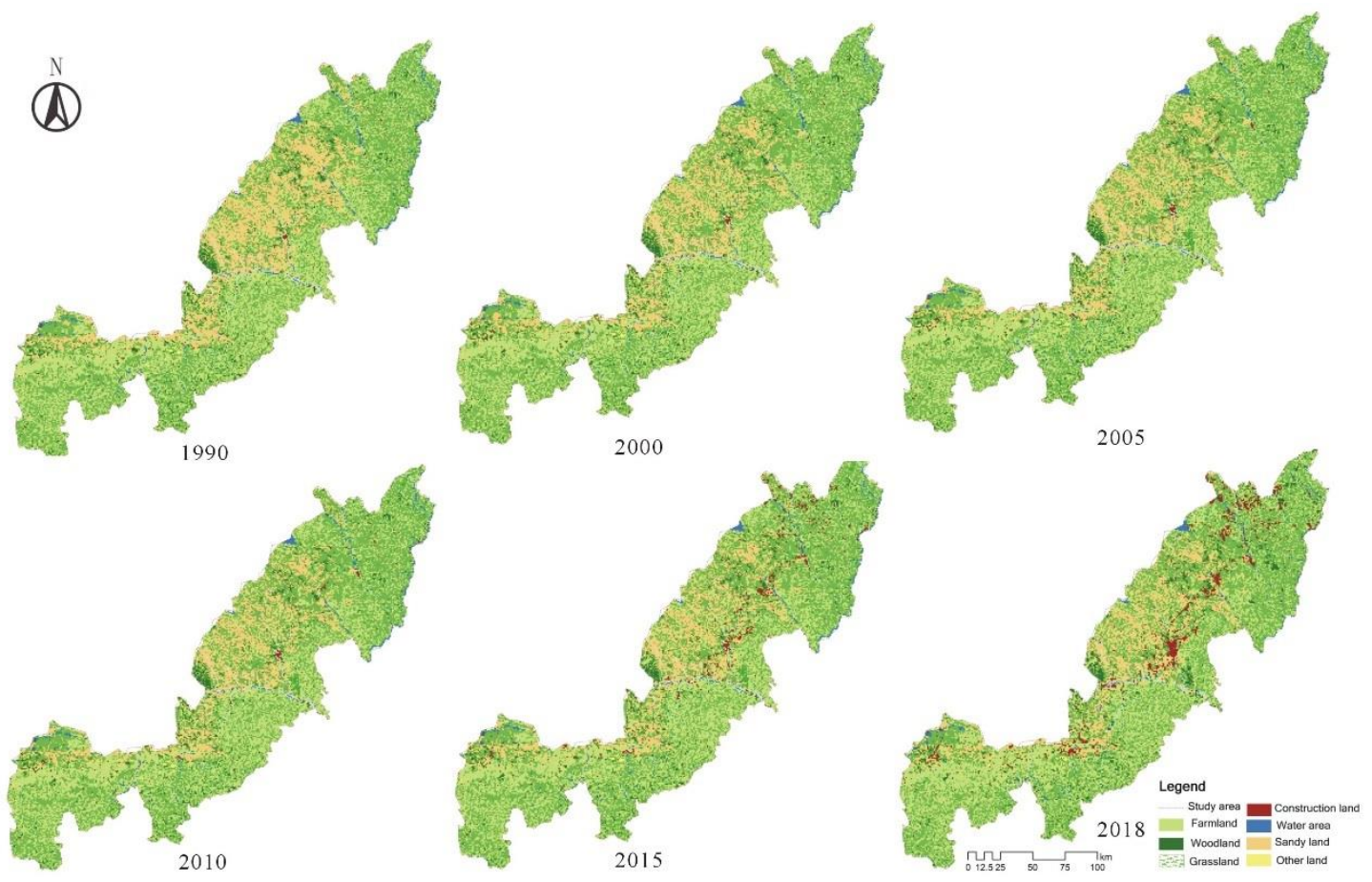

Fig.2 Land use maps of the study area from 1990 to 2018 
The transition matrix, which is a classic tool for detecting LULC changes, was employed in this study for exploring LULC changes in the ANS. An extended transition matrix was conducted for each pair of compared datasets. The maps for the initial period and a subsequent period were overlaid to generate a matrix that indicated the categorical transition in LULC over time (Pontius et al. 2004; Manandhar et al. 2010; Li et al. 2010). To better display data transfer in and out, the transfer matrix of land use was obtained using ArcGIS software and visualized as a Sankey diagram (Figure 3) with data flow direction. The Sankey diagram, which is also known as the Sankey energy balance diagram, is a specific type of flow chart in which the width of the extended branch corresponds to the size of data flow. This diagram was divided into five periods from 1990 to 2018. Figure 3 indicates that different types of land use in each period were transferred out and in. The highest frequency of data conversion was obtained for the period 2015-2018, followed by 1990-2000.

It is worth noting that the most frequent conversion between various types of land use occurred during 2015-2018 (mainly grassland, farmland, and sand). However, a certain balance existed between the transfer in and transfer out, and the final change proportion was not significant. The final change proportions for grassland, farmland, and sand were $1.3 \%,-2.7 \%$, and $-8 \%$, respectively. Of all land types, only the area of sandy land decreased continually. Since 1990, the sand area in the ANS decreased from 5909.2 to $4114.8 \mathrm{~km}^{2}$, with a total decrease of $30.4 \%$. The main transferred-out type of sandy land was grassland before 2010 and farmland after 2010. Moreover, construction land exhibited the highest increase in area, from $89.5 \mathrm{~km}^{2}$ in 1990 to $1016.4 \mathrm{~km}^{2}$ in 2018 (11.4 times increase).

As above mentioned, the main transferred-out type of sandy land was grassland before 2010 and farmland after 2010. In line with climatic conditions and rural living habits in the ANS, numerous pastures and considerable cultivated land are distributed in this area. Irrespective of whether the sandy 

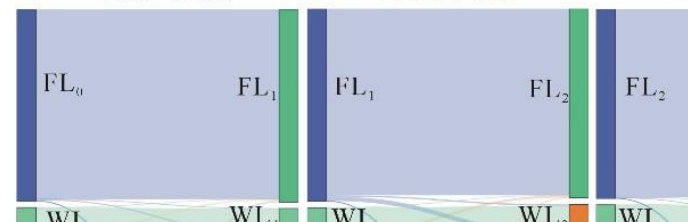

$\mathrm{FL}_{3}$
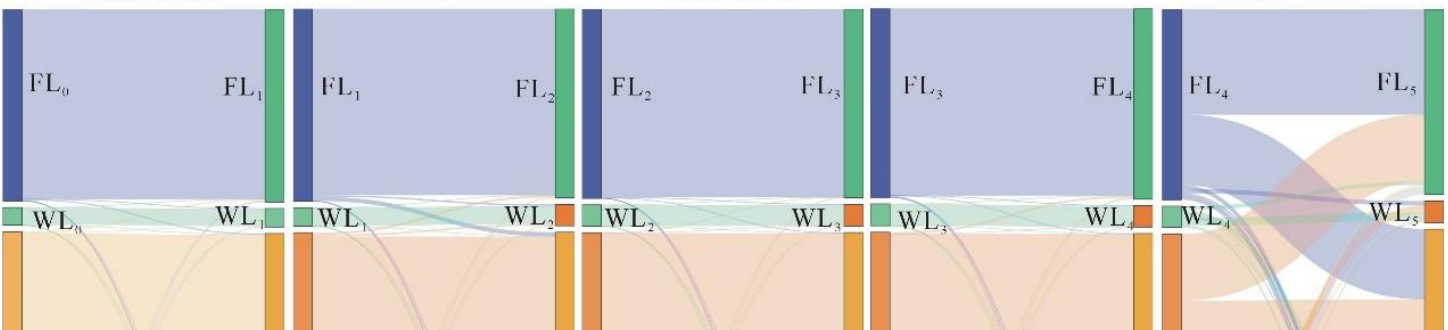

WL
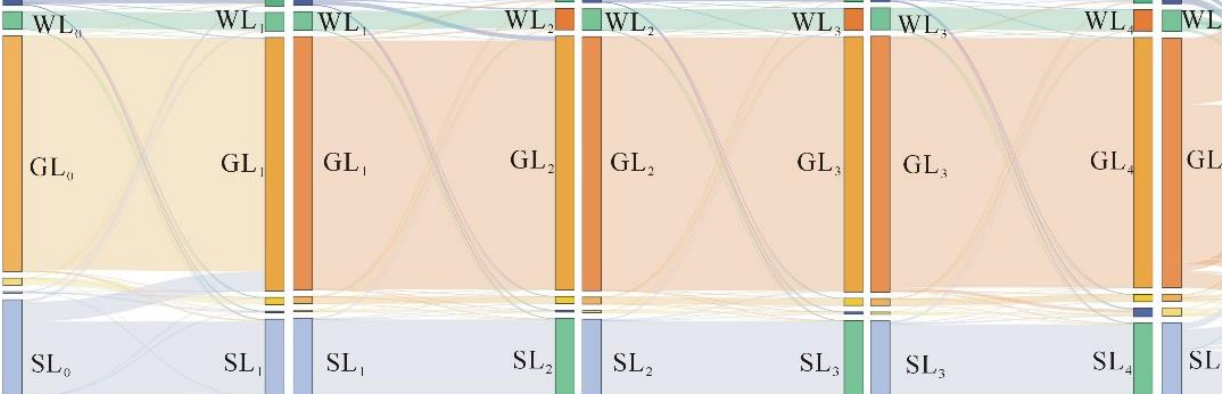

Note: FL denotes farmland, WL denotes woodland, GL denotes grassland, and SL denotes sandy land.

Fig.3 Sankey map of land use type conversion

\section{5}

\subsection{Spatial and temporal evolution characteristics of the NDVI}

Remote sensing data of the monthly average NDVI from 2000 to 2018 were obtained. The NDVI

exhibited a fluctuating trend over 19 years but an increasing overall trend. The NDVI increased from 0.196 in 2000 to 0.371 in 2018 . The total increase in the NDVI was $89.3 \%$, with an average annual increase of $4.7 \%$. After 2000 , the highest obtained NDVI value was 0.594 . This value was obtained in 2013. The annual maximum NDVI value was consistent with the overall trend of the annual average

NDVI value. The annual maximum and annual average NDVI values exhibited growth trends. The annual average NDVI value exhibited a relatively stable growth, with a slope of 0.0092 . The maximum NDVI value exhibited a higher volatility and more significant growth trend than the annual average NDVI value did. The slope of the trend of the maximum NDVI value was 0.0132 . The average annual NDVI of the entire ecotone was 0.279 .

In terms of NDVI distribution within year, the vegetation coverage increased significantly after May. 

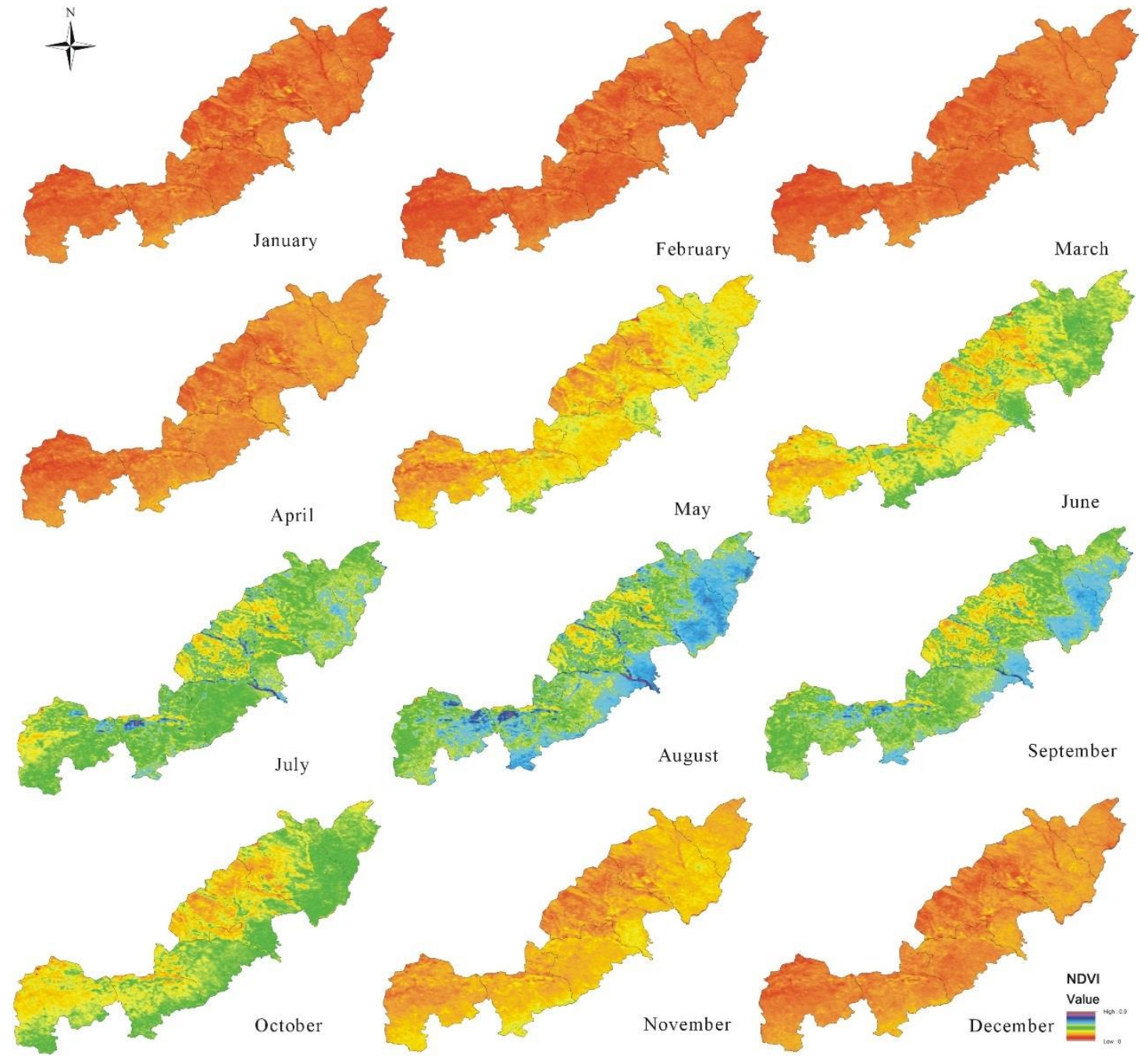

Fig.4 Distribution of the NDVI in the ANS within year

Due to differences in natural conditions and geographical characteristics, the vegetation coverage

concentrated in the southeast of the ANS. The vegetation coverage in the northwest was relatively low,

which is consistent with the distribution of loess and desert from southeast to northwest; thus, the 
the middle of the ANS was lower than that in other regions. Ultimately, the evolution of the NDVI indicated that the vegetation coverage in the entire ecotone gradually improved, which is beneficial for the ecological improvement of the ecotone.

\subsection{Dynamic relationships of sandy land, water consumption and NDVI}

\subsubsection{Analysis for stationarity and cointegration test}

The stationarity of standardized time series of the total water consumption $(T C)$, agricultural water consumption $(A C)$, sandy area $(S A)$, and NDVI $(N V)$ of the study area was examined. To avoid data fluctuation and eliminate possible heteroscedasticity, the data were first subjected to logarithm processing. The obtained data sequence was then subjected to ADF testing. According to the results of ADF test (Table 1), the data sequence was stable if the prob. value was less than $0.05(95 \%$ confidence interval) and the ADF statistic was less than the critical values of $1 \%, 5 \%$, and $10 \%$ significance levels. According to Table 1, all data sequences were nonstationary in the original sequence state. The prob. values of $\log (T C), \log (A C)$, and $\log (N V)$ were less than 0.05 after the first-order difference; thus, these sequences reached a stable state. Only the $\log (S A)$ sequence reached a stable state after the second-order difference. Considering that only the same order stationary may prevent pseudo regression, the secondorder difference was applied to all data sequences to obtain the stationary sequence. 
Table 1 Stationarity test results for each variable

\begin{tabular}{|c|c|c|c|c|c|c|}
\hline \multirow{3}{*}{ Sequence } & \multirow{3}{*}{ ADF-Statistic } & \multirow{3}{*}{ Prob. Value } & \multirow{2}{*}{\multicolumn{3}{|c|}{ Critical values }} & \multirow{3}{*}{ Conclusion } \\
\hline & & & & & & \\
\hline & & & $1 \%$ & $5 \%$ & $10 \%$ & \\
\hline $\log (T C)$ & -0.795659 & 0.79561 & -3.857386 & -3.040391 & -2.660551 & Unstable \\
\hline $\operatorname{Vlog}(T C)$ & -4.686907 & 0.0001 & -2.708094 & -1.962813 & -1.606129 & Stable \\
\hline $\mathrm{V}^{\prime} \log (T C)$ & -4.443680 & 0.0003 & -2.754993 & -1.970978 & -1.603693 & Stable \\
\hline $\log (A C)$ & -3.404071 & 0.0248 & -3.857386 & -3.040391 & -2.660551 & Unstable \\
\hline $\operatorname{Vlog}(A C)$ & -6.951639 & 0.0000 & -2.708094 & -1.962813 & -1.606129 & Stable \\
\hline $\mathrm{V}^{\prime} \log (A C)$ & -4.289001 & 0.0004 & -2.754993 & -1.970978 & -1.603693 & Stable \\
\hline $\log (S A)$ & 4.801633 & 1.0000 & -3.920350 & -3.065585 & -2.673459 & Unstable \\
\hline $\operatorname{Vlog}(S A)$ & 1.480889 & 0.9582 & -2.728252 & -1.966270 & -1.605026 & Unstable \\
\hline $\mathrm{V}^{\prime} \log (S A)$ & -5.601733 & 0.0000 & -2.728252 & -1.966270 & -1.605026 & Stable \\
\hline $\log (N V)$ & 0.067579 & 0.9521 & -3.920350 & -3.065585 & -2.673459 & Unstable \\
\hline $\operatorname{Vlog}(N V)$ & -3.405363 & 0.0020 & -2.708094 & -1.962813 & -1.606129 & Stable \\
\hline $\mathrm{V}^{\prime} \log (N V)$ & -6.714835 & 0.0000 & -2.728252 & -1.966270 & -1.605026 & Stable \\
\hline
\end{tabular}

Note: $\mathrm{V}$ refers to the first-order difference and $\mathrm{V}$ refers to the second-order difference.

302 After the differential processing of time series to make them stable, data sequences may lack long-

304 the causal relationship described by a regression equation is pseudo regression, that is, to test whether a

305 stable relationship exists among variables. In Johansen cointegration test, the maximum likelihood

306 estimation is used to analyze cointegration relationships among multiple variables.

307 As presented in Table 2, when the number of cointegration equations was 0 , the trace statistics and 308 maximum eigenvalue statistics were 107.8306 and 55.35650, respectively, which are greater than the 309 critical value for a significance level of 5\%. Therefore, the original hypothesis of "zero cointegration relationships" is rejected. The results of the trace statistics test and Max-Eigen statistics test indicated 
311 that cointegration relationships, that is, long-term stable equilibrium relationships, existed among the sequences. These relationships were not affected by short-term fluctuations.

Table 2 Results of the Johansen multivariate cointegration test

\begin{tabular}{ccccc}
\hline \multicolumn{5}{c}{ Trace test } \\
\hline $\mathrm{H}_{0}$ & Statistic & Trace Statistic & 0.05 critical value & Proc. Value \\
\hline None $*$ & 0.975093 & 107.8306 & 40.17493 & 0.0000 \\
At most $1 *$ & 0.855498 & 52.47411 & 24.27596 & 0.0000 \\
At most $2 *$ & 0.683380 & 23.45716 & 12.32090 & 0.0005 \\
At most $3 *$ & 0.338838 & 6.203644 & 4.129906 & 0.0151 \\
\hline H & & Max-eigenvalue test & & Proc. Value \\
\hline None $*$ & 0.975039 & Max-Elgen Statistic & 0.05 critical value & 0.0000 \\
At most $1 *$ & 0.855498 & 29.01696 & 24.15921 & 0.0007 \\
At most $2 *$ & 0.683380 & 17.25081 & 17.79730 & 0.0039 \\
At most $3 *$ & 0.338838 & 6.206344 & 11.22480 & 0.1051 \\
\hline
\end{tabular}

314 Note: * indicates rejection of the original hypothesis at a significance level of $5 \%$.

\subsubsection{Construction of VAR model}

317 is too short, the dynamic relationship between variables cannot be fully reflected. Moreover, if the lag

318 length is too long, the degree of freedom can decrease and the validity of the estimated model parameters

319 may be affected. Therefore, a balance must be found between the lag period and the degree of freedom.

320 Different information criteria, including the Final prediction error (FPE), Akaike information criterion

321 (AIC), Schwartz information criterion (SC), Hannan-Quinn (HQ) criterion, and likelihood ratio (LR)

322 test, were used to calculate the lag length for the VAR model. The test results (Table 3) indicate that the maximum lag recommended by the information criteria is 2 . 
Table 3 Lag length selection for the VAR model

\begin{tabular}{ccccccc}
\hline lag & LogL. & LR & FPE & AIC & SC & HQ \\
\hline 0 & 106.5353 & NA & $1.36 \mathrm{e}-11$ & -13.67137 & -13.48256 & -13.67339 \\
1 & 124.5452 & 24.01314 & $1.15 \mathrm{e}-11$ & -13.93935 & -12.99529 & -13.94941 \\
2 & 166.4638 & $33.53488^{*}$ & $6.90 \mathrm{e}-13 *$ & $-17.393517 *$ & $-15.69585^{*}$ & $-17.41327^{*}$ \\
\hline
\end{tabular}

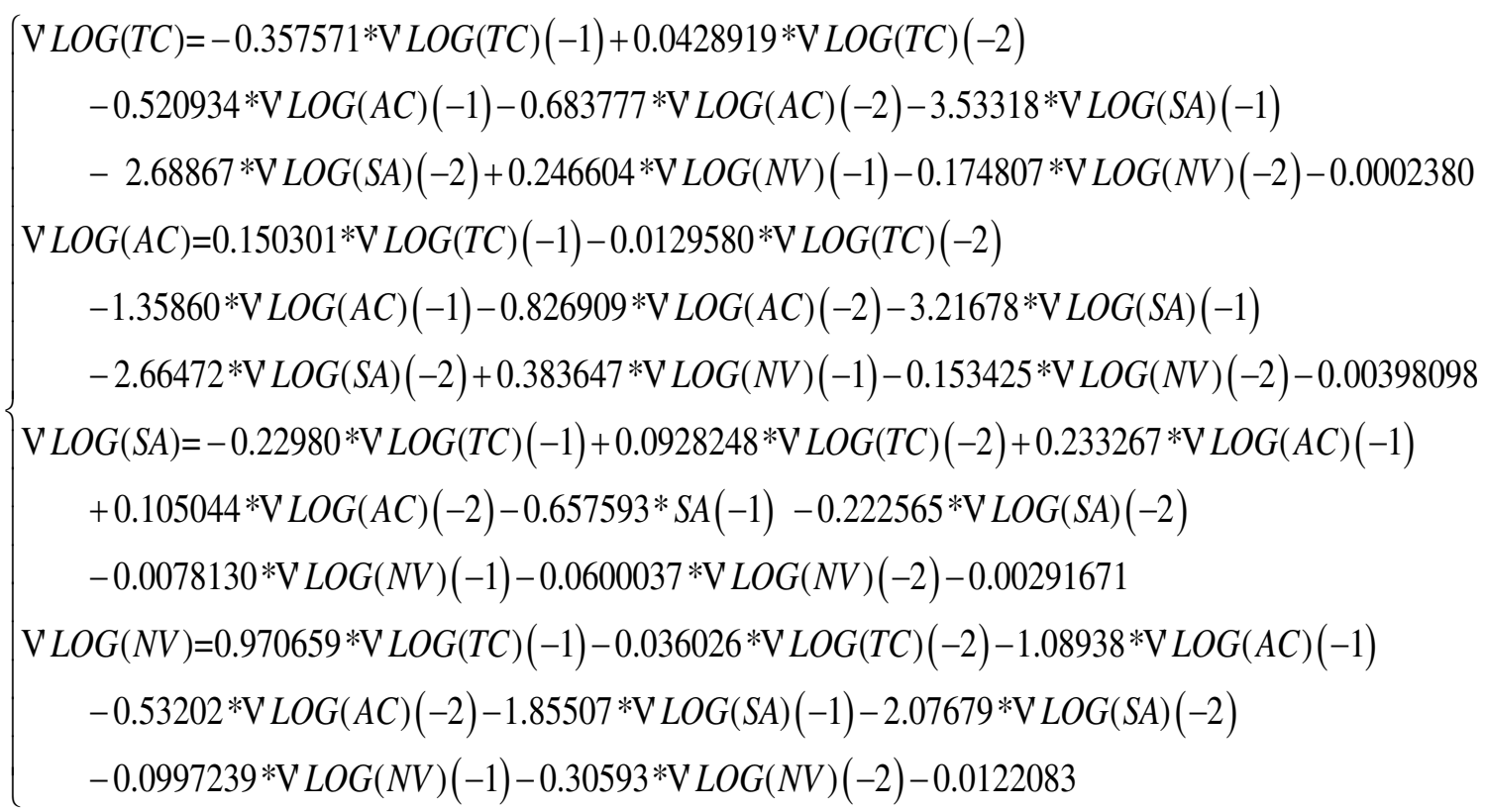

\subsubsection{Analysis of impulse response and relative contribution}

328 The relationships among the variables were investigated by determining shocks in one variable and

examining whether these shocks were transmitted to other variables. The aforementioned investigation

331 Results in Figures 5 reveal that one of the four variables $(\mathrm{V} \log (T C), \mathrm{V} \log (A C), \mathrm{V} \log (S A)$,

$333 \mathrm{~V} \log (S A)$, and $\mathrm{V} \log (N V)$ on other variables were marginally stronger and longer than those of 
of sand area and vegetation coverage with the water consumption were significant. With the reduction of sandy land converted into vegetation cover, then the increase of vegetation coverage will be the direct factor causes the increase of water consumption. The change of sandy land area is an indirect factor. The results show that the response of water consumption to the change of NDVI is relatively stronger.

$$
\text { Furthermore, } \mathrm{V} \log (T C), \mathrm{V} \log (A C) \text {, and } \mathrm{V} \log (S A) \text { responded to a positive } \mathrm{V} \log (N V)
$$
shock begin with the horizontal line and after one step for each point of the sample. Similarly, the responses of $\mathrm{V} \log (T C)$ and $\mathrm{V} \log (A C)$ to a negative $\mathrm{V} \log (S A)$ shock exhibited a lag of one period. To some extent, water consumption and sand changes can be considered to respond to the vegetation growth in the second year of growth. In other words, the vegetation has an impact on water consumption and sand land after a certain period of growth and accumulation, which performed the characteristic of lagging.

The responses of sandy land to other variables were very significant. No signs of decline were observed over 10 periods, which proved that the responses of sandy land to other variables, especially water consumption ( $\mathrm{V} \log (T C)$ and $\mathrm{V} \log (A C))$, were sensitive and had long-term stability. The response of $\mathrm{V} \log (S A)$ to $\mathrm{V} \log (N V)$ exhibited hysteresis loops and an increasing trend with time, which may have a cumulative effect. Results indicate that the changes in the sandy land area may be negatively affected by NDVI. Thus, the longer the NDVI continues to increase, the greater is its effect on the transformations of the sandy land area. 

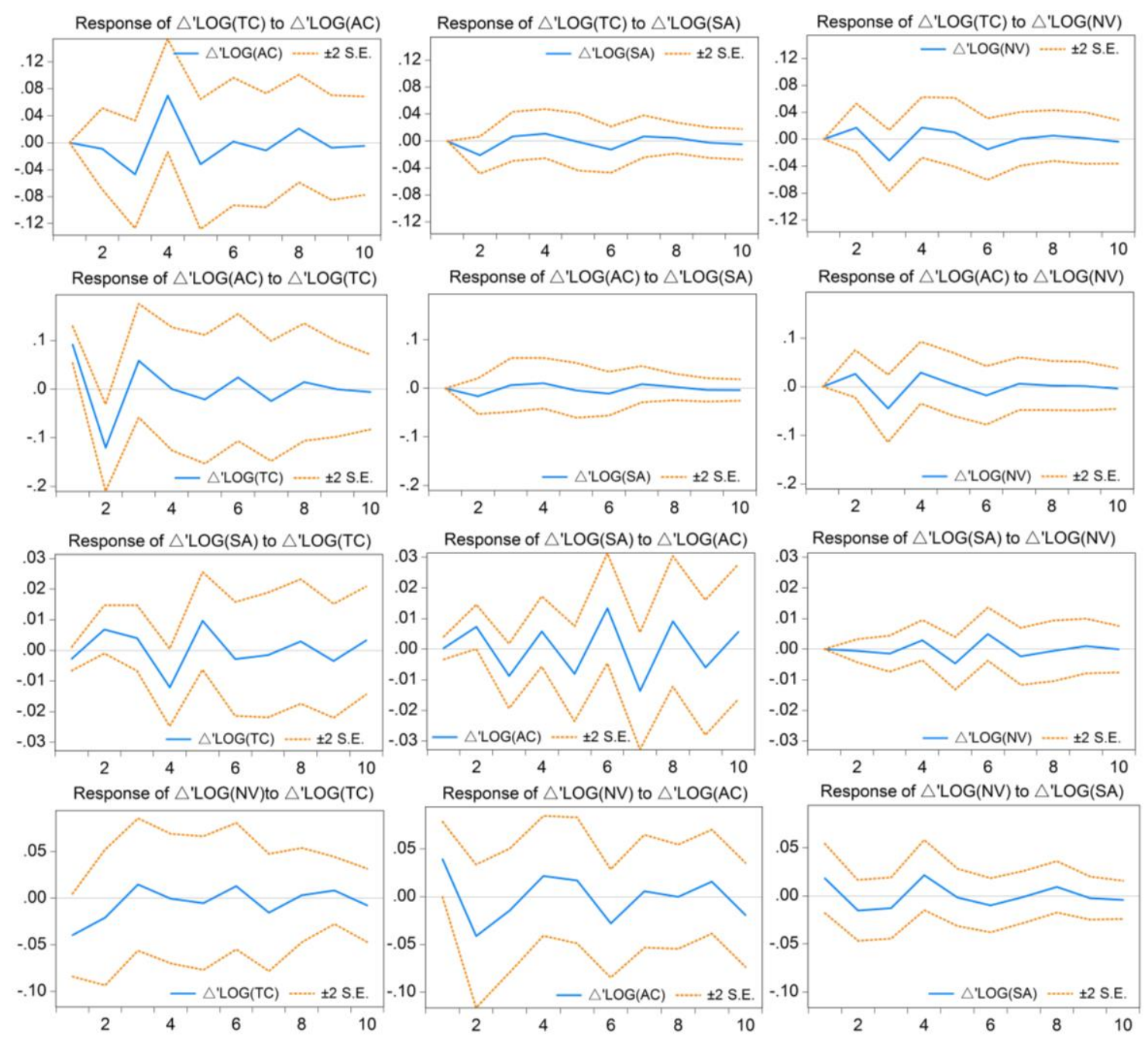

Fig.5 Impulse responses chart

The variance decomposition was employed identify the proportion of variance in one variable caused

by the innovations in other variables in a vector autoregressive (VAR) system. The variance

growth of vegetation coverage has a direct effect on water consumption.

It should be noted that sandy land area and NDVI are closely related to agricultural water consumption, 
364

365

366

367

368

369

370

371

372

373

374

375

376

377

378

379

380

381

382

383

384

385

In ANS, all the water consumption of farmland, woodland and grassland belongs to agricultural water. It can be concluded that the development and utilization measures of sand land in ANS area may be based on large amount of water consumption. Thus, the growth of vegetation is based on investment in water resources. This phenomenon may serve as a reminder that while various measures implemented for combating desertification, it should be alert to the increase of water consumption, which may cause further impact on water shortage areas. Therefore, the scientific management of water resources is an effective strategy for transforming sandy land and achieving vegetation growth. To achieve sustainable development of the local natural system, a balance must be realized among water resources, sandy land area, and vegetation coverage.

(1)

(1) 
Table 4 Variance decomposition results (\%)

\begin{tabular}{|c|c|c|c|c|c|c|c|c|}
\hline \multicolumn{5}{|c|}{ Variance Decomposition of $\mathrm{V} \log (T C)$} & \multicolumn{4}{|c|}{ Variance Decomposition of AC } \\
\hline Period & $\mathrm{V}^{\prime} \log (T C)$ & $\mathrm{V}^{\prime} \log (A C)$ & $\mathrm{V}^{\prime} \log (S A)$ & $\mathrm{V}^{\prime} \log (N V)$ & $\mathrm{V}^{\prime} \log (T C)$ & $\mathrm{V}^{\prime} \log (A C)$ & $V^{\prime} \log (S A)$ & $\mathrm{V}^{\prime} \log (N V)$ \\
\hline 1 & 1 & 0 & 0 & 0 & 88.14 & 11.86 & 0.00 & 0.00 \\
\hline 2 & 92.98 & 0.72 & 3.80 & 2.50 & 88.04 & 8.27 & 1.01 & 2.68 \\
\hline 3 & 72.86 & 15.30 & 3.24 & 8.59 & 80.93 & 9.82 & 0.94 & 8.31 \\
\hline 4 & 54.58 & 34.78 & 2.94 & 7.70 & 67.91 & 21.86 & 1.08 & 9.15 \\
\hline 5 & 52.40 & 37.16 & 2.76 & 7.68 & 64.75 & 25.55 & 1.06 & 8.64 \\
\hline 6 & 51.94 & 36.19 & 3.41 & 8.46 & 64.43 & 25.11 & 1.31 & 9.15 \\
\hline 7 & 52.09 & 36.05 & 3.55 & 8.30 & 64.60 & 24.87 & 1.45 & 9.07 \\
\hline 8 & 51.19 & 37.05 & 3.55 & 8.22 & 64.27 & 25.31 & 1.45 & 8.97 \\
\hline 9 & 51.06 & 37.17 & 3.57 & 8.20 & 64.17 & 25.39 & 1.48 & 8.96 \\
\hline 10 & 50.98 & 37.13 & 3.65 & 8.24 & 64.12 & 25.41 & 1.50 & 8.97 \\
\hline \multicolumn{5}{|c|}{ Variance Decomposition of $V^{\prime} \log (S A)$} & \multicolumn{4}{|c|}{ Variance Decomposition of $\mathrm{V}^{\prime} \log (N V)$} \\
\hline Period & $\mathrm{V} \log (T C)$ & $\mathrm{V}^{\prime} \log (A C)$ & $\mathrm{V}^{\prime} \log (S A)$ & $\mathrm{V}^{\prime} \log (N V)$ & $\mathrm{V}^{\prime} \log (T C)$ & $\mathrm{V}^{\prime} \log (A C)$ & $V^{\prime} \log (S A)$ & $\mathrm{V}^{\prime} \log (N V)$ \\
\hline 1 & 12.63 & 0.22 & 87.15 & 0.00 & 19.07 & 1892 & 4.04 & 0.57 .98 \\
\hline 2 & 29.58 & 29.16 & 41.10 & 0.16 & 18.72 & 30.74 & 5.29 & 45.24 \\
\hline 3 & 24.98 & 46.21 & 27.94 & 0.87 & 18.10 & 28.41 & 5.92 & 47.58 \\
\hline 4 & 45.46 & 34.27 & 17.97 & 2.30 & 16.59 & 29.65 & 8.95 & 44.80 \\
\hline 5 & 46.47 & 34.20 & 14.46 & 4.87 & 16.08 & 30.52 & 8.60 & 44.80 \\
\hline 6 & 36.15 & 46.19 & 11.18 & 6.48 & 15.89 & 33.13 & 8.53 & 42.45 \\
\hline 7 & 29.83 & 55.18 & 9.17 & 5.82 & 17.13 & 32.77 & 8.39 & 41.72 \\
\hline 8 & 28.17 & 57.90 & 8.55 & 5.38 & 17.09 & 32.55 & 8.90 & 41.47 \\
\hline 9 & 27.94 & 58.35 & 8.47 & 5.24 & 17.16 & 33.40 & 8.73 & 40.70 \\
\hline 10 & 27.81 & 58.88 & 8.26 & 5.06 & 17.04 & 34.72 & 8.60 & 39.64 \\
\hline
\end{tabular}


vegetation enhancement project have made steady achievements. For sandy land that has limited water resources and is prone to a high degree of drought, measures, such as artificial vegetation, may lead to the increase of water consumption and then a new crisis of desertification. While affirming the achievements of sand utilization, there are many controversies exist regarding the advantages of turning deserts green, especially considering the scarcity of water resources in these areas. Therefore, the longrun and causal relationship between sandy land, water consumption and vegetation coverage are necessary for explorations.

The ANS, located in the southern margin of the Mu Us desert of China, was taken as the study area in this study. The interactions between sandy land, water consumption and NDVI over a period of 20002018 were examined with VAR model. The results indicate that:

(1) The implementation of desertification control projects makes the ANS experienced frequent land transformation and the sandy area decreased constantly. The main transferred-out type of sandy land was grassland before 2010 and farmland after 2010.

(2) With significant increase, the NDVI ascend from 0.196 in 2000 to 0.371 in 2018 with a ratio of $89.3 \%$. However, its spatial distribution was uneven. Especially in the area along the sandy land distribution, the intensity of human disturbance is high, while the vegetation coverage is low. For further sand control measures, ecological vulnerability should be considered scientifically.

(3) There existed long-term stable equilibrium and causal relationships among water consumption, sandy land and NDVI. Relatively, NDVI has a strong impact on the water consumption and show an increasing trend with time. The increase of NDVI may be the direct factor causes the increase of water consumption, and the change of sandy land area is an indirect factor.

It could be concluded that the development and utilization measures of sand land in ANS area may be 
based on large amount of water consumption. Thus, the growth of vegetation is based on investment in water resources. This phenomenon may serve as a reminder that while various measures implemented for combating desertification, it should be alert to the increase of water consumption, which may cause further impact on water shortage areas. Therefore, the scientific management of water resources is an effective strategy for transforming sandy land and achieving vegetation growth. To achieve sustainable development of the local natural system, a balance must be realized among water resources, sandy land area, and vegetation coverage.

\section{Declarations:}

Ethics approval and consent to participate: Not applicable.

\section{Consent for publication: Not applicable.}

Availability of data and materials: The datasets analyzed during the current study are available in the following data sets. Xu Xinliang. Spatial distribution data set of monthly vegetation index (NDVI) in China. Data registration and publishing system of resource and environmental science data center, Chinese Academy of Sciences ( http://www.resdc.cn/DOI ),2018.DOI:10.12078/2018060602

Competing interests: The authors declare that they have no competing interests.

Funding: This study was supported by the Postdoctoral research and development project of Yellow River Engineering Consulting Co.,Ltd. (Grant No.2020BSHZL04), and the National Key Research and Development Program of China (Grant No. 2017YFC0404402, 2018YFC1508404).

Authors' contributions: MZ and YW designed the concept and methodology developed in this article and selected the case study, together with the other co-authors; SL prepared the initial draft manuscript and analyzed the results under supervision of YW and PZ.; HL and RL made the final editing and revision 
work. All authors read and approved the manuscript to submission.

\section{References}

Adenomon, M. O., Ojehomon, V. E., Oyejola, B. A. (2013) Modelling The Dynamic Relationship Between Rainfall and Temperature Time Series Data In Niger State, Nigeria. Mathematical theory and modeling 3(4):53-70. https://doi.org/10.7176/MTM

Amiraslani, F., \& Dragovich, D. (2011) Combating desertification in Iran over the last 50 years: an overview of changing approaches. Journal of Environmental Management 92(1):1-13. DOI: 10.1016/j.jenvman.2010.08.012

An, Y., Gao, W., \& Gao, Z. (2014). Characterizing land condition variability in Northern China from 1982 to 2011. Environmental Earth Sciences 72(3):663-676. DOI:10.1007/s12665-013-2987-6

Bai Z., Cui J. (2019). Desertification and its causes in Mu Us Desert in recent 2000 years, 39(2): 177 185. DOI: $10.7522 / \mathrm{j}$. issn.1000-694X.2019.00007

Bonkoungou E G. (1996) Drought, desertification, and water management in sub-Saharan Africa. United Nations University Press, New York, NY, E.-U, 165-180.

Chen, C., Park, T., Wang, X. et al. (2019) China and India lead in greening of the world through land-use management. Nature Sustainability 2.2: 122-129. https://doi.org/10.1038/s41893-019-0220-7

Dickey, D. A., \& Fuller, W. A. (1979) Distribution of the Estimators for Autoregressive Time Series with a Unit Root. Journal of the American Statistical Association, 74(366):427-431. https://doi.org/10.1080/01621459.1979.10482531

Dickey, D. A., \& Fuller, W. A. (1981). Likelihood Ratio Statistics for Autoregressive Time Series with a Unit Root. Econometrica, 49(4), 1057-1072. https://doi.org/10.2307/1912517 
Engle, R. F., \& Granger, C. W. (1987 Co-integration and Error Correction: Representation, Estimation, and Testing. Econometrica, 55(2):251-276. https://doi.org/10.2307/1913236

Gao, T. M. (2006). Econometric analysis and modeling-EVIEWS examples and cases. Beijing, Tsinghua University Press

Huang, Y., Wang, N., He, T., Chen, H., Zhao, L. (2009). Historical desertification of the Mu Us Desert, Northern China: A multidisciplinary study. Geomorphology, 110(3), 108-117. https://doi.org/10.1016/j.geomorph.2009.03.020

Jiyuan, L., Zengxiang, Z., Xinliang, X., Wenhui, K., Wancun, Z., Shuwen, Z., et al. (2010) Spatial patterns and driving forces of land use change in China during the early 21 st century. Journal of Geographical Sciences, 20(4):483-494. DOI:10.1007/s11442-010-0483-4

Johansen, S., \& Juselius, K. (1990) Maximum likelihood estimation and inference on cointegration with application to the demand for money. Oxford Bulletin of Economics and Statistics, 52:169-210. DOI:10.1111/j.1468-0084.1990.mp52002003.x

Ju, C., Cai, T., \& Yang, X. (2008) Topography-based modeling to estimate percent vegetation cover in semi-arid Mu Us sandy land, China. Computers and Electronics in Agriculture, 64(2):133-139. DOI:10.1016/j.compag.2008.04.008

Karnieli, A., Qin, Z.H., Wu, B., Panov, N., Yan, F. (2014) Spatio-temporal dynamics of land-use and land-coverin the $\mathrm{Mu}$ Us Sandy Land, China, using the change vector analysis technique. Remote Sensing. 6 (10), 9316-9339. DOI:10.3390/rs6109316

Kumar, U., Prakash, A., \& Jain, V. K. (2009) A Multivariate Time Series Approach to Study the Interdependence among O3, NOx, and VOCs in Ambient Urban Atmosphere. Environmental Modeling \& Assessment, 14(5):631-643. DOI:10.1007/s10666-008-9167-1 
Li, J., Zhao, Y., Liu, H., \& Su, Z. (2016) Sandy desertification cycles in the southwestern Mu Us Desert in China over the past 80 years recorded based on nebkha sediments. Aeolian Research, 100-107. DOI:10.1016/j.aeolia.2015.12.003

Li, Y., Cao, Z., Long, H., Liu, Y., \& Li, W. (2017) Dynamic analysis of ecological environment combined with land cover and NDVI changes and implications for sustainable urban-rural development: The case of $\mathrm{Mu}$ Us Sandy Land, China. Journal of Cleaner Production, 142(PT.2):697-715. DOI:10.1016/j.jclepro.2016.09.011

Liu Q, Zhang Q, Yan Y, Zhang X, Niu J, Svenning Jens-Christian. (2020) Ecological restoration is the dominant driver of the recent reversal of desertification in the Mu Us Desert (China), Journal of Cleaner Production, Doi: 10.1016/j.jclepro.2020.122241.

Liu, J., Li, S., Ouyang, Z., Tam, C., \& Chen, X. (2008) Ecological and socioeconomic effects of China's policies for ecosystem services. Proceedings of the National Academy of Sciences of the United States of America, 105(28):9477-9482. DOI:10.1073/pnas.0706436105.

Lu, M. (2001). Vector autoregression (VAR)- an approach to dynamic analysis of geographic processes. Geografiska Annaler Series B-human Geography, 83(2):67-78. DOI:10.2307/491057.

Mcmillin, W. D. (1991). The Velocity of M1 in the 1980s: Evidence from a Multivariate Time Series Model. Southern Economic Journal, 634-648. Doi.org/10.2307/1059778.

Meng, J., Xiang, Y., Yan, Q., Mao, X., \& Zhu, L. (2015) Assessment and management of ecological risk in an agricultural-pastoral ecotone: case study of Ordos, Inner Mongolia, China. Natural Hazards, 79(1):195-213. DOI:10.1007/s11069-015-1836-1.

Quiggin, J. (2001). Environmental economics and the Murray-Darling river system. Australian Journal of Agricultural and Resource Economics, 45(1), 67-94. DOI:10.1111/1467-8489.00134. 
Reynolds, J. F., Smith, D. M. S., Lambin, E. F., Turner, B. L., Mortimore, M., Batterbury, S. P. J., et al. (2007) Global Desertification: Building a Science for Dryland Development. Science, 316(5826), 847-851. DOI:10.1126/science.1131634.

Runnstrom, M. (2003). Rangeland development of the Mu Us Sandy Land in semiarid China: an analysis using Landsat and NOAA remote sensing data. Land Degradation \& Development, 14(2), 189-202.

Sims, C. A. (1980). Macroeconomics and reality. Econometrica. 48 (1):1-48. DOI:10.1002/1dr.545.

Wu, B., \& Ci, L. (1999). Developing stages and causes of desertification in the Mu Us Sand land. Science Bulletin, 44(9), 845-849. DOI:10.1007/BF02885034.

Wu, B., \& Ci, L. J. (2002). Landscape change and desertification development in the Mu Us Sandland, Northern China. Journal of Arid Environments, 50(3):429-444. DOI:10.1006/jare.2001.0847.

Wu, S., Li, J., Zhou, W., Lewis, B. J., Yu, D., Zhou, L. et al. (2018) A statistical analysis of spatiotemporal variations and determinant factors of forest carbon storage under China's Natural Forest Protection Program. Journal of Forestry Research, 29(2):415-424. https://doi.org/10.1007/s11676-017-0462-z.

Wu, Z., Wu, J., He, B., Liu, J., Wang, Q., Zhang, H., \& Liu, Y. (2014) Drought Offset Ecological Restoration Program-Induced Increase in Vegetation Activity in the Beijing-Tianjin Sand Source Region, China. Environmental Science \& Technology, 48(20):12108-12117. DOI:10.1021/es502408n.

Xiyan, M. (2012). A Multi-level Analysis of the Driving Forces of Land Use Changes in Mu-Us Desert in Recent 30 Years: Case Study of Uxin Banner, Inner Mongolia. Journal of Basic Science and Engineering. 20 (9):54-66 (in Chinese). DOI:10.3969/j.issn.1005-0930.2012.s1.006.

Xueying H , Guang Y, Fucang Q, et al. (2019). Spatial and Temporal Dynamic Patterns of Sandy Land in $\mathrm{Mu}$ Us in the Last 30 Years. Research of soil and water conservation, 26(5):144-150, 157 (in 
523 Yin, R., \& Yin, G. (2010) China’s Primary Programs of Terrestrial Ecosystem Restoration: Initiation, Implementation, and Challenges. Environmental Management 45(3): 429-441. and Their Effects on Rural System in China's Mountainous Regions: The Case of Shuanghe Village

Zhang, G., Dong, J., Xiao, X., Hu, Z., \& Sheldon, S. (2012) Effectiveness of ecological restoration projects in Horqin Sandy Land, China based on SPOT-VGT NDVI data. Ecological Engineering, Environmental Earth Sciences, 44(5):530-534. DOI:10.1007/s00254-003-0788-z. 
Figures

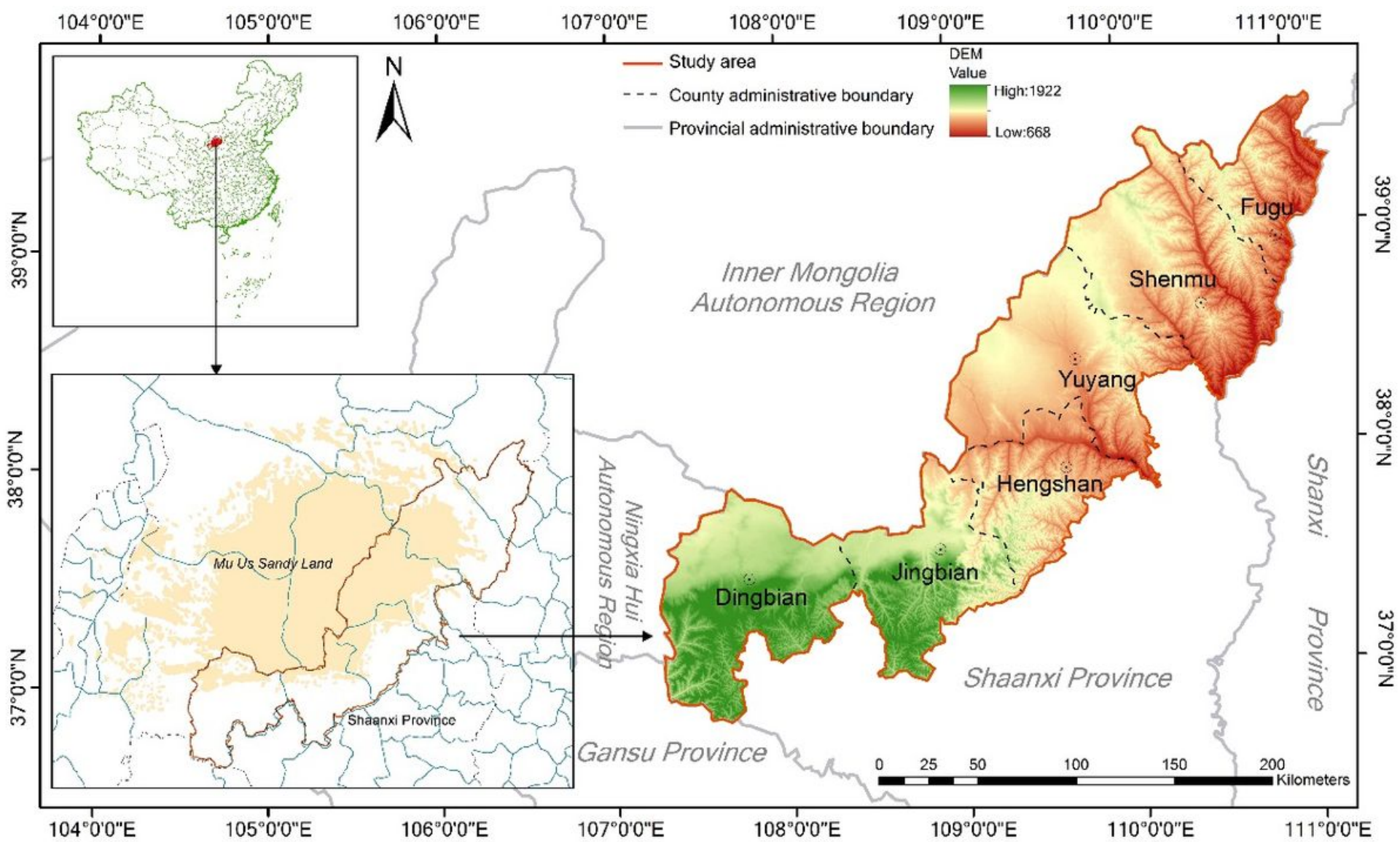

Figure 1

Location of the study area Note: The designations employed and the presentation of the material on this map do not imply the expression of any opinion whatsoever on the part of Research Square concerning the legal status of any country, territory, city or area or of its authorities, or concerning the delimitation of its frontiers or boundaries. This map has been provided by the authors. 

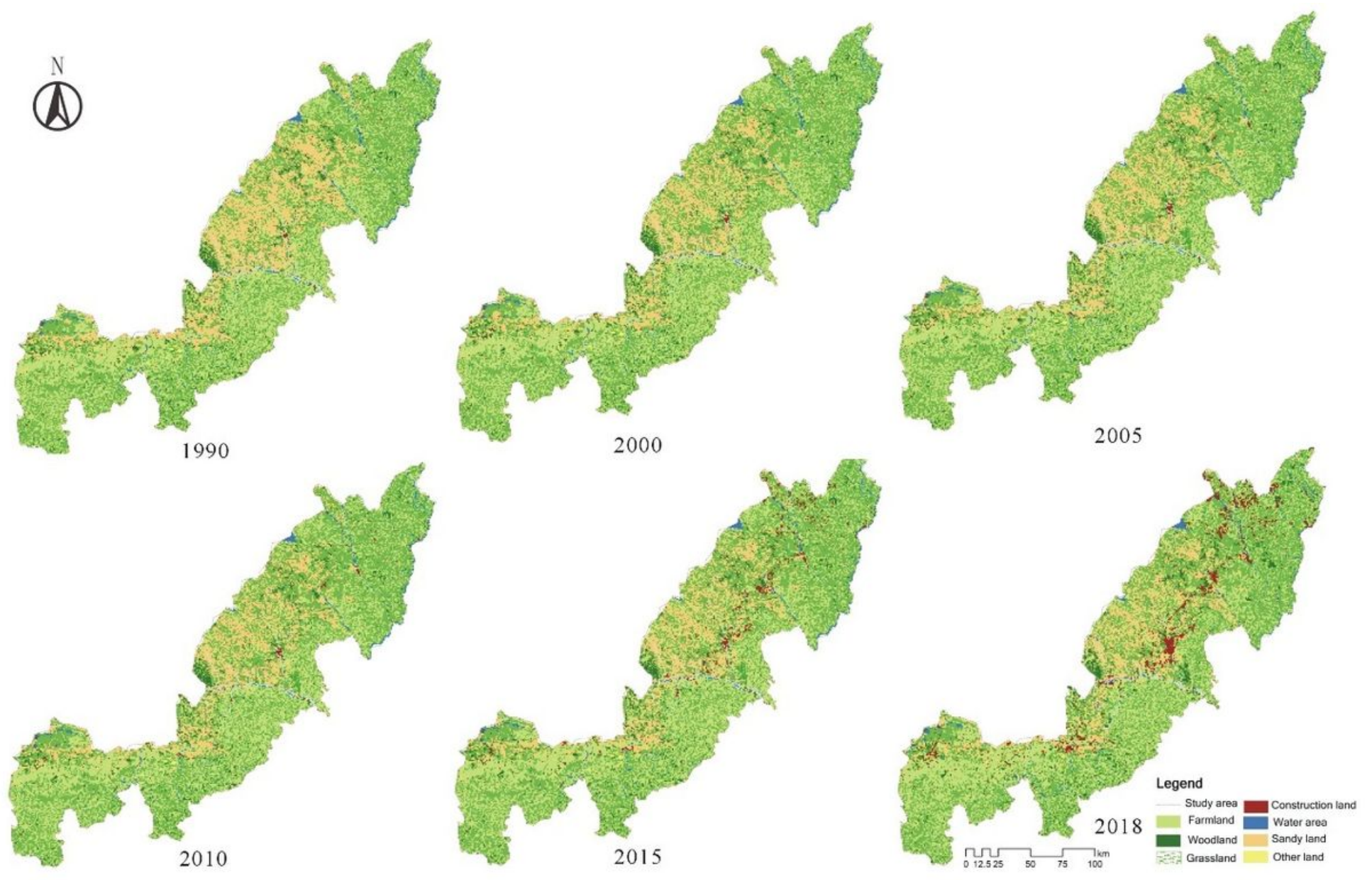

\section{Figure 2}

Land use maps of the study area from 1990 to 2018 Note: The designations employed and the presentation of the material on this map do not imply the expression of any opinion whatsoever on the part of Research Square concerning the legal status of any country, territory, city or area or of its authorities, or concerning the delimitation of its frontiers or boundaries. This map has been provided by the authors. 


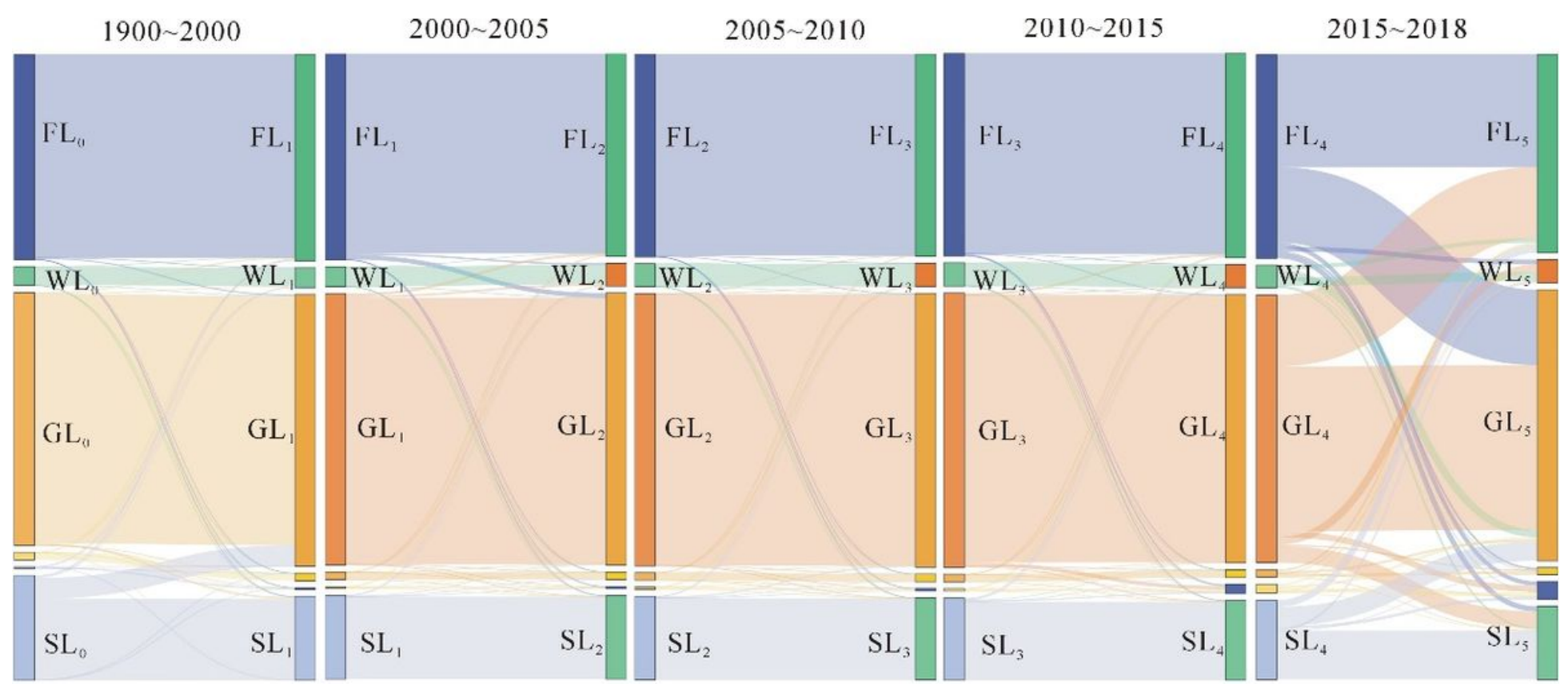

Figure 3

Sankey map of land use type conversion Note: FL denotes farmland, WL denotes woodland, GL denotes grassland, and SL denotes sandy land. 


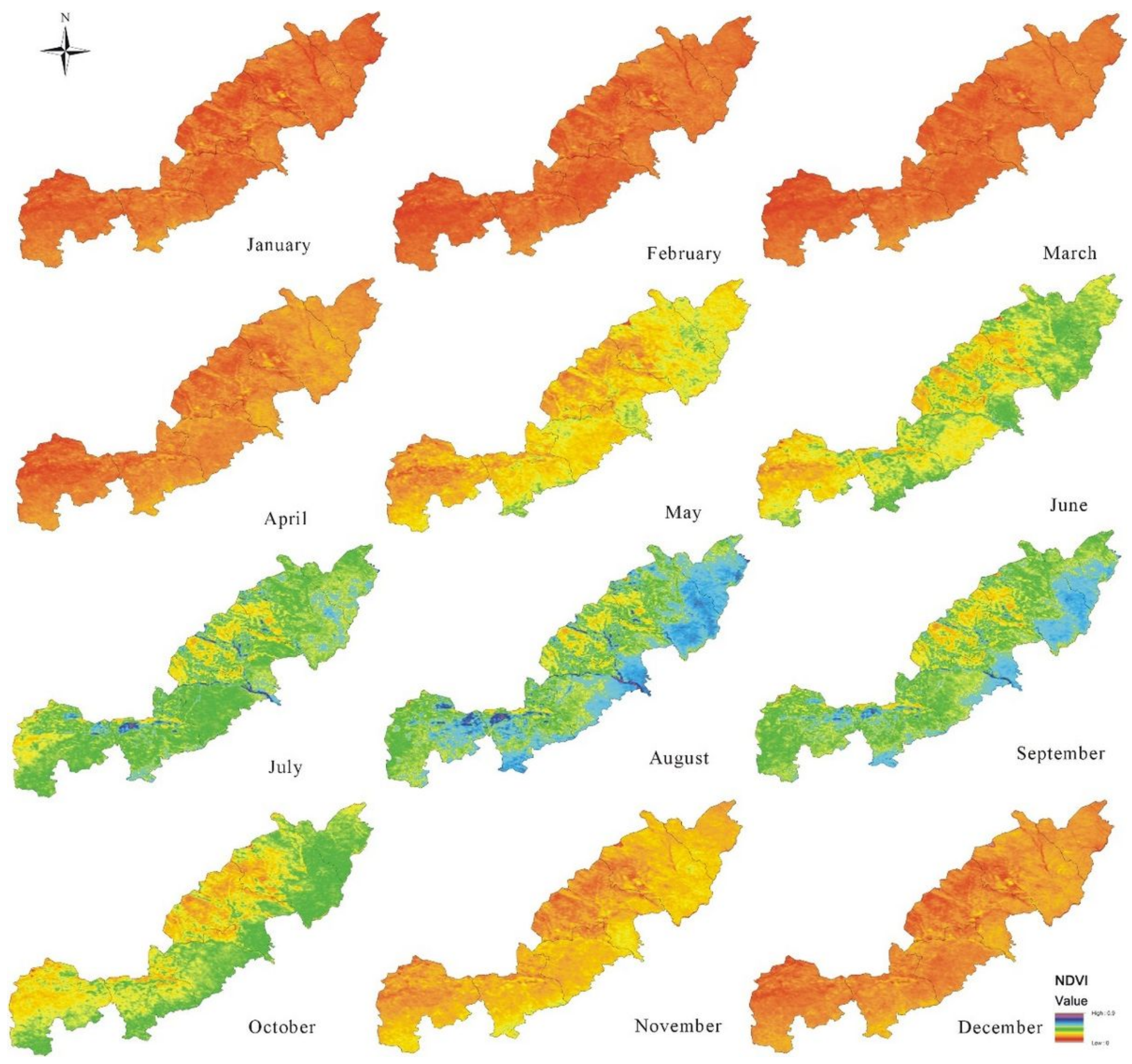

Figure 4

Distribution of the NDVI in the ANS within year Note: The designations employed and the presentation of the material on this map do not imply the expression of any opinion whatsoever on the part of Research Square concerning the legal status of any country, territory, city or area or of its authorities, or concerning the delimitation of its frontiers or boundaries. This map has been provided by the authors. 

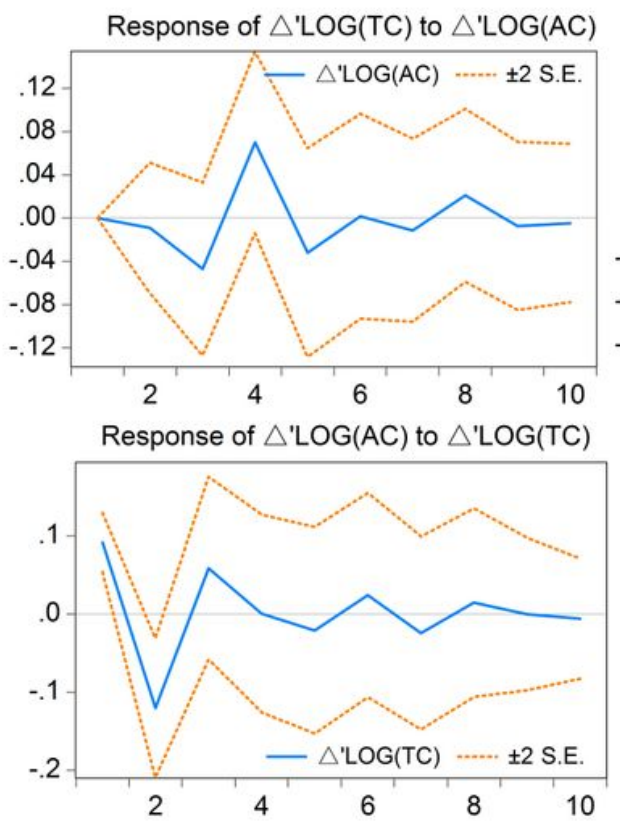

\section{)}

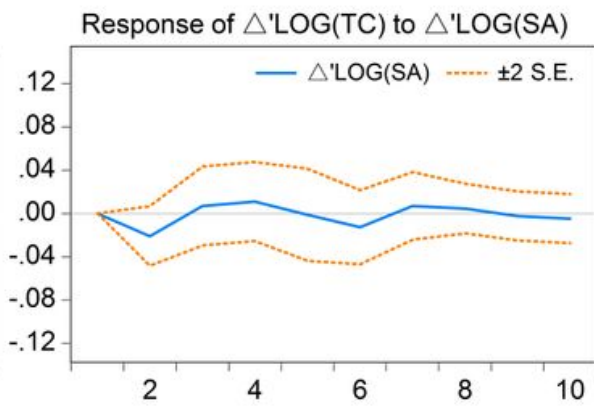

Response of $\triangle{ }^{\prime} \mathrm{LOG}(\mathrm{AC})$ to $\triangle{ }^{\prime} \mathrm{LOG}(\mathrm{SA})$
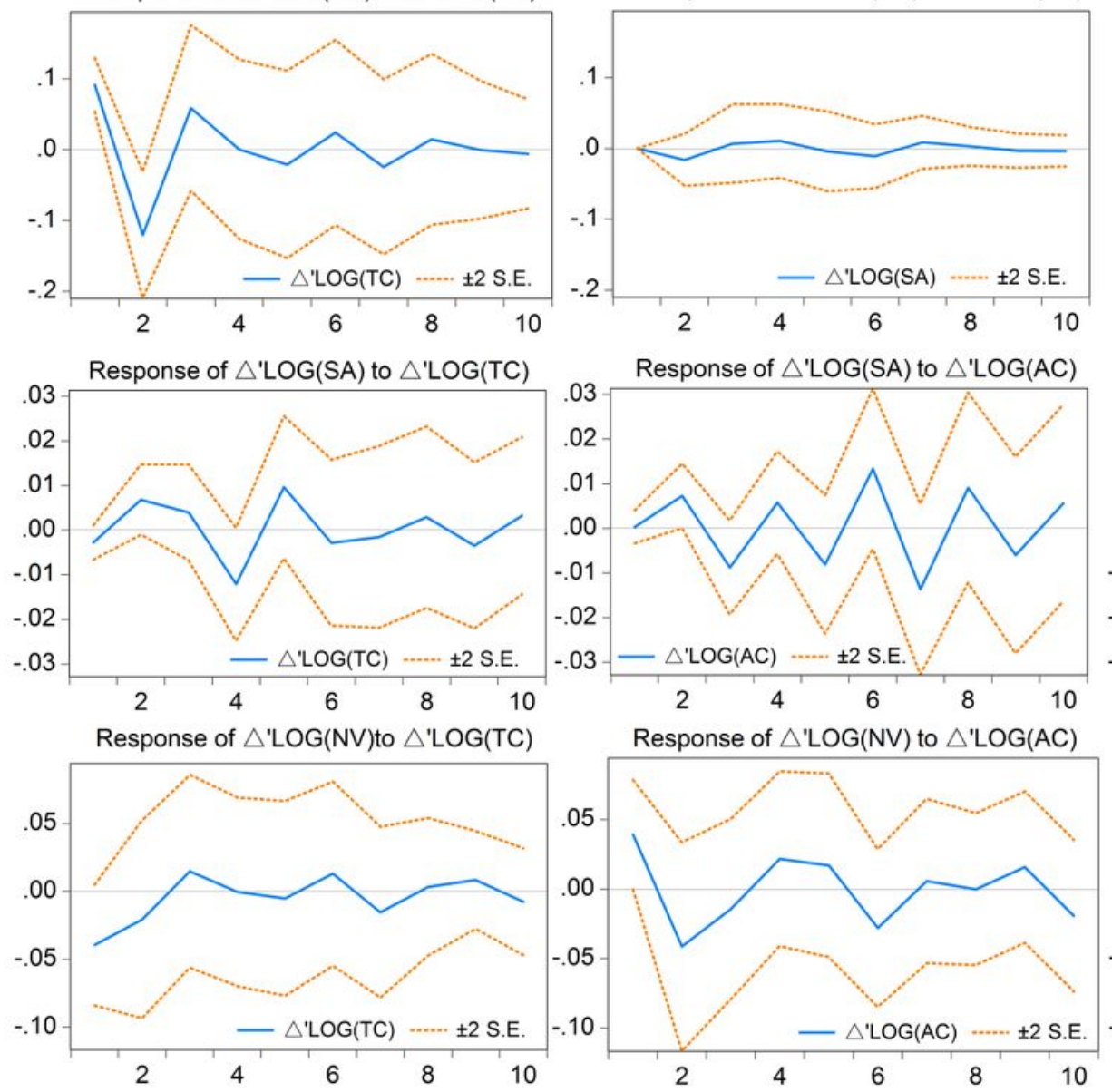

Response of $\triangle^{\prime} \mathrm{LOG}(\mathrm{TC})$ to $\triangle^{\prime} \mathrm{LOG}(\mathrm{NV})$

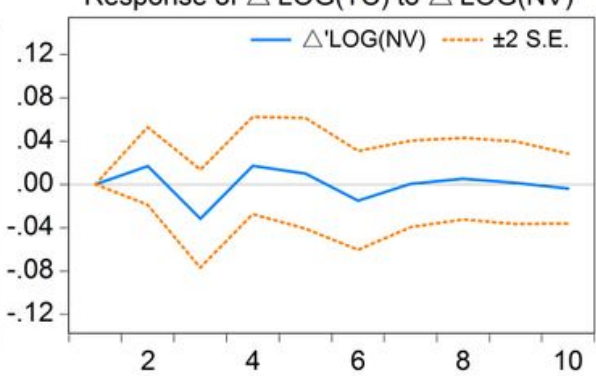

Response of $\triangle$ 'LOG(AC) to $\triangle$ 'LOG(NV)

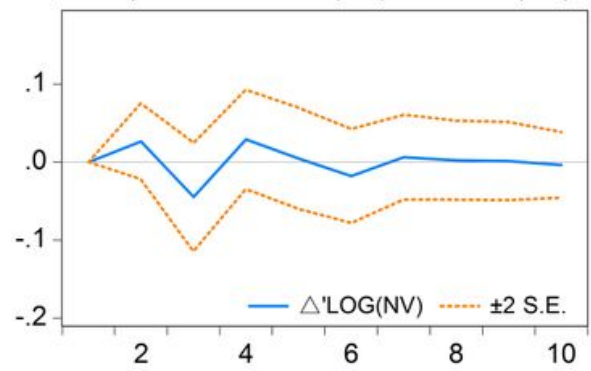

Response of $\triangle$ 'LOG(SA) to $\triangle$ 'LOG(NV)

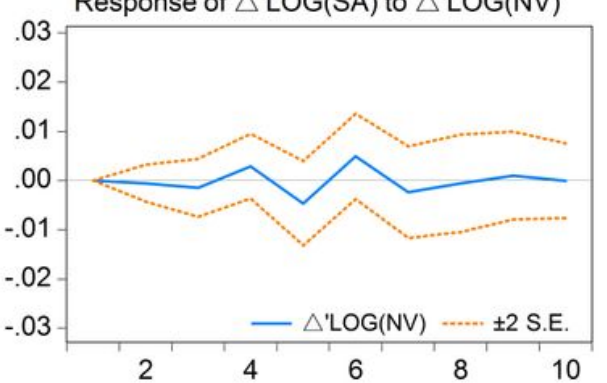

Response of $\triangle$ LOG(NV) to $\triangle$ 'LOG(SA)

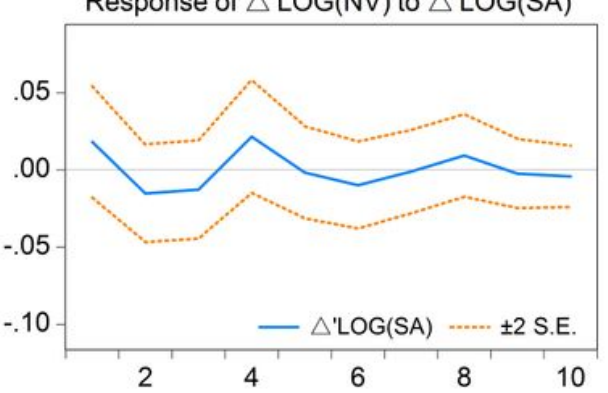

\section{Figure 5}

Impulse responses chart 